\title{
Da positivação à antropização degradante da Mata do Louzeiro: uma análise socioambiental à luz da lei de SNUC
}

\author{
From legal affirmation to degrading anthropization of the Louzeiro's bush: a socio-environmental \\ analyses considering the SNUC law \\ De la positividad a la antropización degradante de Mata do Louzeiro: un análisis socioambiental a \\ la luz de la ley SNUC
}

Recebido: 16/12/2020 | Revisado: 24/12/2020 | Aceito: 28/12/2020 | Publicado: 02/01/2021

Agda Nara Tavares Bandeira

ORCID: https://orcid.org/0000-0002-2279-1873 Universidade Federal de Campina Grande, Brasil E-mail: agdanara@hotmail.com

Paula Ângela Brunet Freitas ORCID: https://orcid.org/0000-0002-1508-2606 Universidade Federal de Campina Grande, Brasil E-mail: paulaangelabf@gmail.com

Thiago Ferreira Estrela

ORCID: https://orcid.org/0000-0002-1974-3694 Universidade Federal de Campina Grande, Brasil

E-mail: thiiago_estrela@ hotmail.com

\begin{abstract}
Resumo
Considerando a Mata do Louzeiro, área verde localizada na zona urbana da cidade de Campina Grande - Paraíba, como uma unidade que necessita devida regulamentação e preservação, o presente trabalho busca ressaltar os principais conflitos ambientais existentes tendo como parâmetro de gestão a Lei de SNUC - Sistema Nacional de Unidades de Conservação. Para tanto, procede-se à pesquisa de natureza exploratória e explicativa, com investigação in loco, levantamento de dados e discussão teórica sobre sua legalização no ordenamento jurídico. Apesar da existência de legislação local que garante a área como especial, de preservação permanente desde a década de 1990, não há fiscalização ou implementação de políticas públicas que inibam os principais agravos ambientais que degradam a região como o desmatamento, a deposição irregular de resíduos sólidos, a supressão de vegetação nativa, a retirada de areia e a caça de animais silvestres. A preocupação parte da premissa da necessidade de criação de uma Unidade de Conservação (UC), com a finalidade principal de preservação da natureza e dos recursos naturais locais, identificando através de diagnóstico, a degradação sofrida pela área e a relação de simbiose e de exploração da comunidade a ela pertencente. Um processo onde todos os atores envolvidos compreendam sua importância e participem da sua conservação, pautados no bem-estar humano, na educação ambiental, na gestão participativa e no desenvolvimento sustentável.
\end{abstract}

Palavras-chave: Unidades de conservação; Mata do Louzeiro; Degradação; Lei de SNUC; Legislação ambiental.

\begin{abstract}
Taking into consideration the Louzeiro's bush, green area situated in the city area of Campina Grande - Paraíba, as an location which requires proper regulation and preservation, this work aims to highlight the current environmental challenges in this place, considering as a management parameter the SNUC law - Brazilian legislation that deals with Conservation Units. For this purpose, proceeds with exploratory and explanatory research, based on on-the-spot visits, data collection and a theoretical discussion about its adequacy to the to the legal order. despite the existence of local legislation assuring the area a especial protection, considered in permanent preservation since the 1990s, there is not enough monitoring or implementing of public policies which inhibit the main problems that increasingly degrade the environment as deforestation, irregular deposit of solid waste on the surface, vegetation suppression, extraction of sand and the hunting of wild animals. This concern is based on the premise of the need to create a Conservation Unit, with the main object of preservation of nature and local natural resources, diagnosing the degradation of the area and the symbiotic relationship between the involved population. A process where all the parties involved becomes able to understand its importance to participate and improve conservation values, ruled by the well-being of the population, environmental education, participative management and sustainable development.
\end{abstract}

Keywords: Conservation units; Louzeiro's Bush; Degradation; SNUC Law; Environmental legislation. 


\begin{abstract}
Resumen
Considerando la Mata do Louzeiro, área verde ubicada en el área urbana de la ciudad de Campina Grande - Paraíba, como una unidad que necesita una adecuada regulación y preservación, el presente trabajo busca resaltar los principales conflictos ambientales teniendo como parámetro de gestión la Ley SNUC - Sistema Nacional de Unidades de Conservación. Para ello, la investigación es de carácter exploratorio y explicativo, con investigación in situ, recolección de datos y discusión teórica sobre su legalización en el ordenamiento jurídico. A pesar de la existencia de legislación local que garantiza el área como especial, de preservación permanente desde la década de 1990, no existe fiscalización o implementación de políticas públicas que inhiban los principales problemas ambientales que degradan la región, como la deforestación, depósito irregular de residuos sólidos, la supresión de la vegetación nativa, la remoción de arena y la caza de animales salvajes. La preocupación parte de la premisa de la necesidad de crear una Unidad de Conservación (UC), con el objetivo principal de preservar la naturaleza y los recursos naturales locales, identificando a través del diagnóstico, la degradación que sufre el área y la relación de simbiosis y exploración de la comunidad a la que pertenece. Un proceso, donde todos los actores involucrados comprenden su importancia y participan en su conservación, guiados por el bienestar humano, la educación ambiental, la gestión participativa y el desarrollo sostenible.
\end{abstract}

Palabras clave: Unidades de conservación; Mata do Louzeiro; Degradación; Ley SNUC; Legislación medioambiental.

\title{
1. Introdução
}

A Unidade de Conservação é um espaço territorial delimitado, incluindo as águas jurisdicionais, com características naturais relevantes, legalmente instituído pelo Poder Público para a proteção da natureza, com objetivos e limites definidos, sob regime específico de administração - ao qual se aplicam adequadas garantias de proteção (SNUC, 2000).

Um acontecimento importante nos últimos anos, na área de conservação do meio ambiente, foi a aproximação de técnicos e acadêmicos com a sociedade em geral. A participação das comunidades e lideranças da região, além dos diferentes atores envolvidos com as unidades, em todas as etapas do planejamento tem sido, frequentemente, executada através de parcerias entre entidades não-governamentais e o Poder Público.

Na porção semiárida nordestina, existem 23 unidades de conservação que apresentam alguma forma de vegetação de caatinga. Estas unidades de conservação são, em sua grande maioria, bastante antigas e, por ocasião de sua criação, não havia uma metodologia de seleção e criação adotada nacionalmente (Silva, 1999)

Na zona urbana de Campina Grande - PB encontra-se a Floresta do Louzeiro, ambiente de reconhecida potencialidade biótica e abiótica, histórica e paisagística. Protegida por Lei Orgânica Municipal, no Inciso III Art. 269 como área intocável de preservação permanente, "poemas e teorias", embora seja protegido por Lei, este sistema sofre sérios agravos a sua sustentabilidade (Guedes, 2002).

Refletindo sobre esta questão, faz-se necessário desenvolver uma consciência ecológica crítica em relação aos problemas enfrentados pela Floresta do Louzeiro, onde mesmo em meio a legislação vigente, devem ser criadas políticas públicas e estratégias a fim de produzir ações modificantes na preservação e gestão da área degradada.

Dessa forma, o objetivo principal deste estudo consubstanciou-se em ressaltar os principais conflitos ambientais existentes na Mata do Louzeiro, identificando as principais práticas que a degradam e com ela a relação de simbiose e de exploração da comunidade, no sentido de obter os recursos para a sua sobrevivência.

\section{Metodologia}

A presente pesquisa foi realizada na Mata do Louzeiro, área de aproximadamente 60 hectares de vegetação dentro do Município de Campina Grande, Estado da Paraíba, zona pertencente a região do médio curso da Bacia Hidrográfica do Rio Paraíba. 
Classifica-se quanto a seus objetivos, como de natureza exploratória, pois interessa considerar os mais variados aspectos relativos aos conflitos existentes na Mata do Louzeiro, bem como de natureza explicativa, ao recorrer ao método observacional da região para confirmação dos fenômenos locais, através de visitas técnicas.

A pesquisa tem um caráter exploratório e interpretativo dos dados coletados. Por meio da observação in loco foi realizado levantamento dos conflitos e as consequências ao meio em estudo durante o mês de Agosto de 2019, sendo dividido em duas etapas.

Primeiro a visita de campo para exploração da área e registro dos principais pontos de degradação. Essa etapa foi fundamental para relacionar e entender os danos causados na área de estudo. Segundo as pesquisas do tipo bibliográfica e documental, que embasaram os procedimentos que orientaram a elaboração deste artigo, considerando trabalhos escritos e eletrônicos como livros, artigos científicos, bem como documentos, leis e códigos disponíveis em sites do governo municipal e no Portal da Legislação - Planalto, que versam sobre a temática em nosso ordenamento jurídico, observado a qualidade das informações nelas contidas.

A abordagem qualitativa motivou a discussão e investigação sobre a necessidade de análise da Mata do Louzeiro à luz da gestão de unidades de conservação no Brasil. Dessa forma, foi procedida a discussão teórica sobre a positivação da área, sua legalização no ordenamento local, bem como a antropização degradante que a região sofre constantemente - como retratado nas imagens apresentadas - e a análise da Lei de SNUC - Sistema Nacional de Unidades de Conservação.

\section{Resultados e Discussões}

\subsection{Positivação do Louzeiro}

A Mata do Louzeiro é patrimônio de Campina Grande, além de seu valor ambiental, existe nela um valor histórico. Na época, a Cacimba do Louzeiro era ponto de encontro e descanso para os tropeiros que vinham do Sertão e Cariri e lá encontravam sombra e o que beber, outrossim, também foi de extrema importância para a população campinense nos períodos de grande seca, pois oferecia água potável de boa qualidade.

A região também serviu para a fabricação de tijolos de alvenaria que fizeram parte das paredes da igreja matriz de Campina Grande, durante a seca entre os anos de 1791 e 1793, onde o espírito religioso teve forte avivamento, como é descrito no Inquérito Civil número 016/2015 do Ministério Público da Paraíba.

Por muito tempo, a área que compreende atualmente a Mata do Louzeiro fazia parte da zona rural do município de Campina Grande. Seu grande valor ambiental, advém de sua importância dentro de uma região proporcionalmente desprovida de vegetação arbórea, logo, o Sítio Louzeiro, como era percebido à época, desde sempre teve relevância local, seja ambiental ou afetiva para a população que dele usufruía (Lima, 2014).

Não obstante, a região era destinada à exploração para subsistência da população circunvizinha. Práticas como caça, pesca, retirada de madeira, de argila do solo, assim como descarte de resíduos da construção civil, industriais, orgânicos, domésticos e até despejo de esgoto no leito do Riacho das Piabas - afluente do Rio Paraíba localizado na Mata do Louzeiro -, eram costumes dos indivíduos que dependiam ou necessitavam da exploração da área.

O Código de Águas, Decreto n 24.643 de 10 de julho de 1934, marco regulatório da propriedade e dos múltiplos usos da água, bem como o Código Florestal, Lei no 4.771 de 15 de setembro de 1965, instrumento legal que institui o direito de propriedade e restrições de uso para regiões de formações vegetais, são fontes jurídicas que legitimaram a instituição da área da Mata do Louzeiro como zona de proteção ambiental em Campina Grande.

A legitimação dessa área decorreu de suas características inerentes, como a exemplo das caracterizações trazidas tanto pelo Código de Águas, com a presença, proteção e regulação das nascentes como águas públicas de uso comum, quanto pelo 
Código Florestal, que instituiu florestas e formas de vegetação, reconhecidas de utilidade às terras que revestem, também como bens de interesse comum.

Instrumentos que estabeleceram como áreas de preservação permanente, florestas e demais formas de vegetação natural situadas, por exemplo, ao longo dos rios ou de outro qualquer curso d'água, situados ao redor das lagoas, lagos ou reservatórios d'água naturais ou artificiais, e também em áreas de nascentes, mesmo nos chamados "olhos d'água", seja qual for a sua situação topográfica (Brasil, 1965).

As décadas de 1970, 1980 e 1990 são marcadas pelo despertar ecológico, mais exatamente pelas preocupações coletivas acerca do meio ambiente e assuntos como poluição, degradação, consumo, preservação da natureza e o uso dos recursos naturais.

Todo esse contexto, validou a necessidade de se legalizar a Mata do Louzeiro através do instrumento normativo municipal, a Lei Orgânica de Campina Grande de 05 de abril de 1990. Ato normativo este, que estabelece em seu artigo 252, os instrumentos de execução da política municipal de meio ambiente e cria as unidades de conservação tais como áreas de preservação permanente, de proteção ambiental, de relevante interesse ecológico ou cultural, parques municipais, reservas biológicas e estações ecológicas (Campina Grande, 1990).

A supracitada lei, em seu artigo 269, também considera como áreas de preservação permanente, declaradas por lei, as áreas do Açude Velho, Açude de Bodocongó, Rio Bodocongó, Horto Municipal, Floresta de São José da Mata, Feira Central e a Floresta do Louzeiro (Campina Grande, 1990).

Sem embargo, a normatização da Mata do Louzeiro como área de preservação permanente não impediu a degradação que ali existia antes de sua criação, e assim permaneceu, pela falta de fiscalização e efetivação da lei, bem como a falta de implementação de políticas públicas voltadas à educação ambiental da população local, por parte do Poder Público Municipal.

Após 20 anos da Conferência de Estocolmo realizada em 1972, marco dos grandes eventos sobre meio ambiente a nível mundial, em 1992 ocorreu a Conferência das Nações Unidas sobre o Meio Ambiente e o Desenvolvimento, conhecida como a Rio-92, que resultou em diversos acordos voltados para temática ambiental, entre os mais famosos, a Convenção da Biodiversidade e a Agenda 21.

Diante dos debates ambientais internacionais, a gestão municipal da época cria em 1993 a primeira Secretaria de Meio Ambiente do Município de Campina Grande, contudo, a instituição não foi capaz de implementar ações de forma a combater a exploração da área.

Com o constante crescimento da cidade, da urbanização e da população, a zona da Mata do Louzeiro passou a fazer parte do perímetro urbano de Campina Grande, e com ele, diversos problemas passaram a se desencadear, problemas de ordem socioambiental, como ocupações irregulares para construção de moradias, falta de saneamento básico, retirada de lenha para fogueiras, enchentes provocadas pelas cheias do Riacho das Piabas, criminalidade, entre outros, chamaram atenção da Igreja Católica, da Sociedade de amigos do bairro e de pesquisadores que se interessavam em estudar o local, de forma a pressionar o poder público e a imprensa para preservação da Mata.

Após o início dos anos 2000, com o aflorar dos debates e as problemáticas locais ambientais, foi criada a Lei 4.249 de 15 de março de 2005, que autoriza o Poder Municipal a criar o Jardim Botânico de Campina Grande como forma de aplicação da política de preservação do meio ambiente, incentivo ao turismo ecológico bem como a política de orientação à comunidade. Ficando ainda a cargo da Prefeitura Municipal, a escolha do local mais adequado para implantação desse Jardim Botânico (Campina Grande, 2005).

O Plano Diretor Municipal do ano seguinte, por sua vez, já contemplava a área do Jardim Botânico. A Lei Complementar $n^{\circ} 003$ de 09 de outubro de 2006, trouxe em seu artigo 34, as denominadas Zonas Especiais, como áreas do Município, que por características especiais, possuem destinação específica e/ou tratamento diferenciado. 
Dentro dessa classificação, os artigos 42, 43 e 44 trazem as Zonas Especiais de Preservação - ZEP, que tem por subdivisão as Zonas Especiais de Interesse Cultural - ZEIC e as Zonas Especiais de Interesse Ambiental - ZEIA podendo serem estas, áreas de interesse ambiental (ZEIA 1) e áreas de recuperação ambiental (ZEIA 2), a área que compreende a Mata do Louzeiro, então, passa a receber essa classificação por parte do Plano Diretor Municipal (Campina Grande, 2006).

No ano de 2007, com a mobilização para criação do Comitê pró Louzeiro, os movimentos de escolas, ativistas, igrejas, Ministério Público, sociedade civil e outros órgãos, ganharam força e pressionaram o Poder Público para que fossem tomadas medidas que freassem a degradação da Mata e fossem aplicadas políticas públicas de melhorias para população local (Lima, 2014).

Destarte, a Lei Complementar $n^{\circ} 042$ de 24 de setembro de 2009, instituiu o Código de Defesa do Meio Ambiente do Município de Campina Grande, que em seu Capítulo IV, artigo 14 traz como um dos instrumentos da política do meio ambiente o Zoneamento Ambiental do Município, constituído pelas Zonas Especiais de Preservação, estando entre elas a Mata do Louzeiro e Riacho das Piabas (Campina Grande, 2009).

Em meados de 2013, após discussões e debates acerca da criação do Jardim Botânico de Campina Grande, foi então criado seu projeto e definida sua localização, a Mata do Louzeiro.

No entanto, apenas em 2015, a Lei que propriamente cria o Jardim Botânico, Lei $\mathrm{N}^{\circ} 6.250$ de 17 de dezembro de 2015, foi promulgada, compreendendo o Jardim como área protegida por reunir, no todo ou em parte, coleção de plantas vivas e catalogadas afim de sua pesquisa e conservação das espécies, também definindo como sede a Mata do Louzeiro (Campina Grande, 2015).

\subsection{Degradação Antrópica da Mata}

O Louzeiro como importante área de preservação permanente de Campina Grande, já deveria ter sido entendida como uma Unidade de Conservação (UC) há mais tempo, tendo como finalidade principal, a preservação da natureza e dos recursos naturais locais, tendo como parâmetro de gestão a Lei de SNUC.

Pelos dados coletados in loco (Figuras 1 a 4), constata-se que existe de fato um conflito manifestado pelo uso dos recursos naturais, bem como pelo uso da área de preservação ambiental principalmente para exploração da madeira versus o não atendimento da responsabilidade socioambiental da propriedade. Os principais agravos ambientais evidenciados foram: $\mathrm{O}$ desmatamento; deposição irregular de resíduos sólidos; supressão de vegetação nativa; retirada de areia e a caça de animais silvestres.

Figura 1. Mata do Louzeiro.

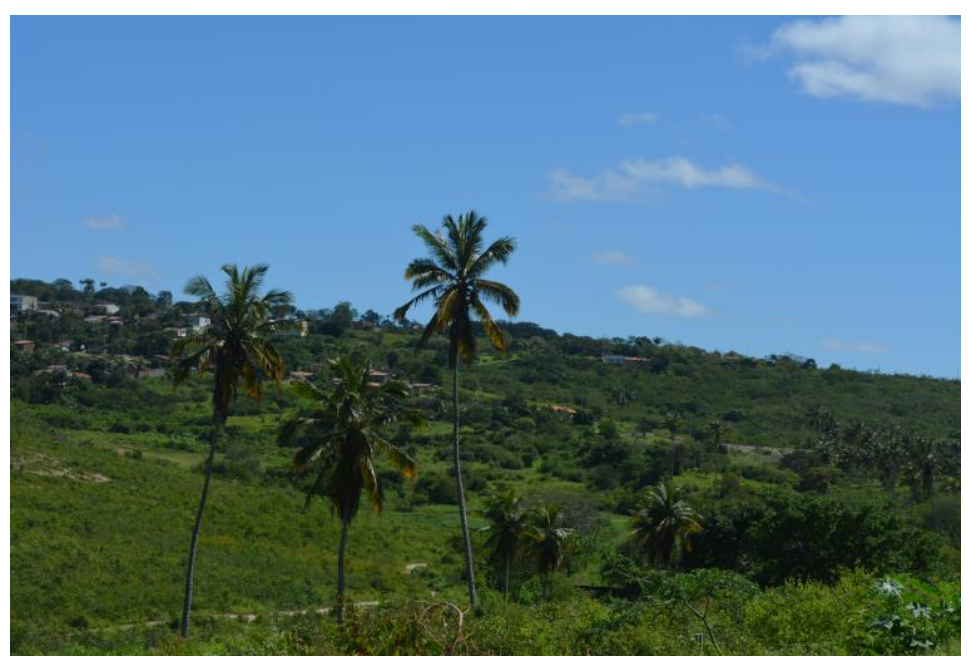

Fonte: Autores (2919). 
Figura 2. Retirada da Argila .

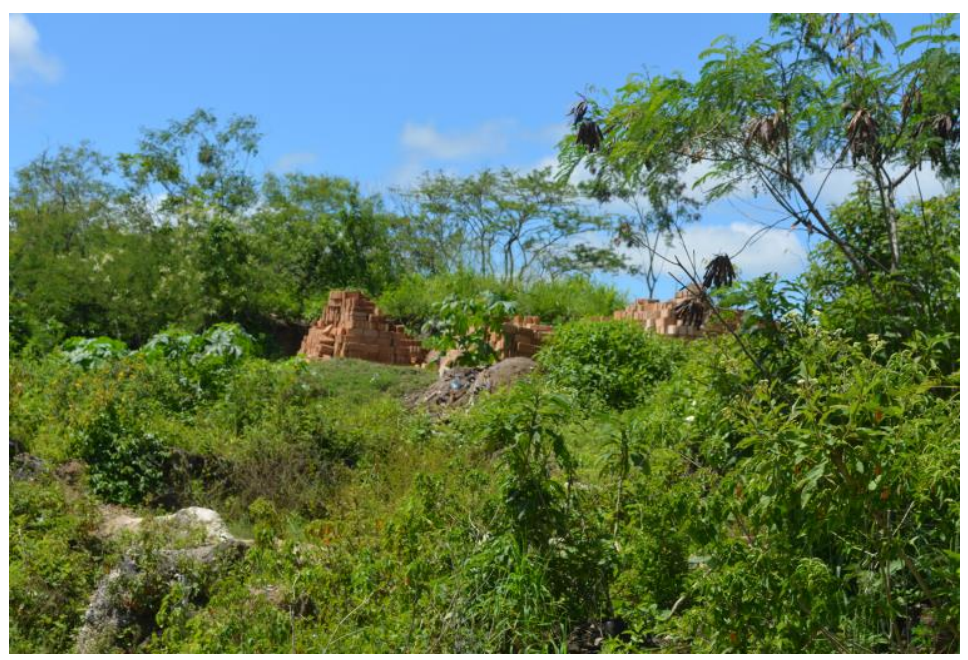

Fonte: Autores (2019).

Figura 3. Deposição de lixo no interior da Mata.

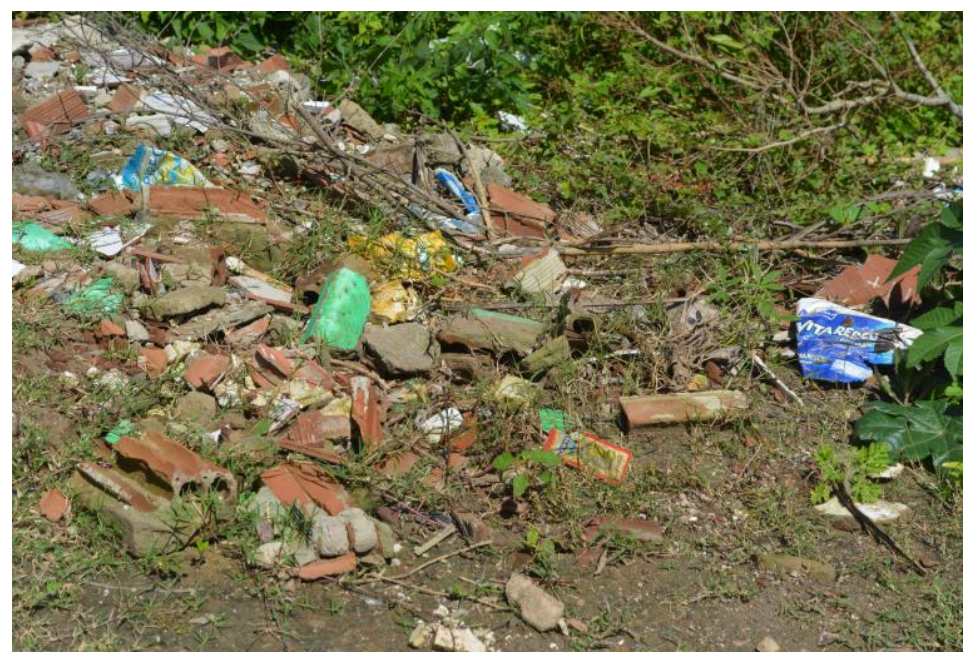

Fonte: Autores (2019).

Figura 4. Retirada da Madeira.

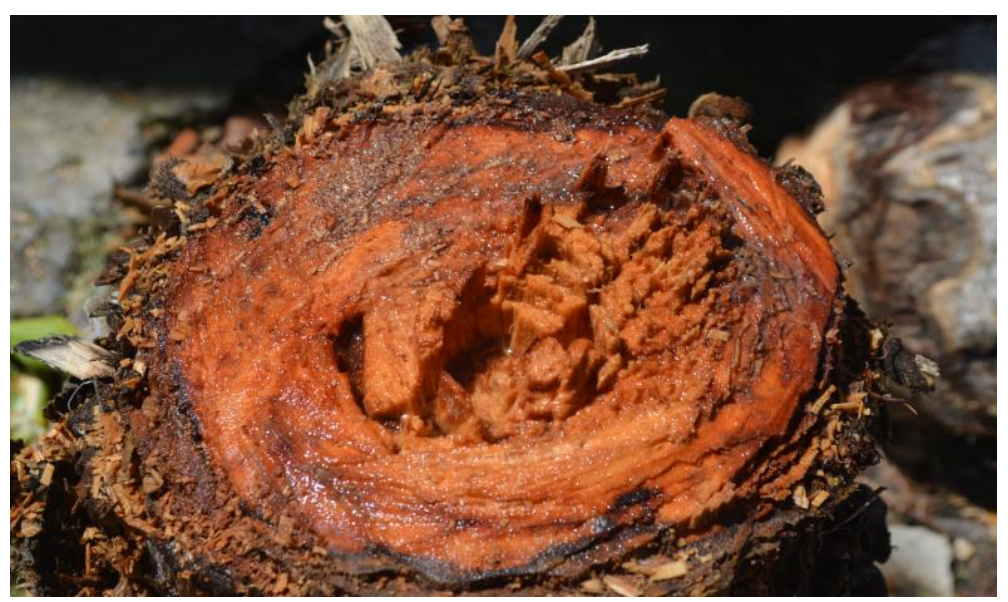

Fonte: Autores (2019). 
Os desmatamentos, por exemplo, podem acabar com hábitats de espécies que dependem deles para viver. A redução da diversidade biológica compromete a sustentabilidade e a disponibilidade permanente dos recursos ambientais. A cada dia que se passa a lista de animais e plantas a beira da extinção aumenta, desaparecem da superfície terrestre, devido, entre outros fatores, à destruição de ecossistemas, à caça e à captura de indivíduos.

A área de estudo apresenta um impacto ao qual deve ser destacado que é o decapeamento do solo para extração de areia, causando erosão do solo e alteração da paisagem. Na medida em que o solo é retirado, tende-se a deixar o lençol freático mais exposto ao ambiente externo facilitando assim a contaminação das águas subterrâneas.

Toda essa degradação ambiental provocada pelas atividades da comunidade que se localiza nas proximidades da Mata do Louzeiro, afeta as condições de sobrevivência das espécies, põe em risco as populações de plantas e consequentemente de animais presentes no ambiente. Os diferentes tipos de pressões que estão sendo geradas sobre os recursos naturais destroem comunidades inteiras e tem implicações diretas sobre o equilíbrio dos ecossistemas mundiais.

Para reverter a situação, é necessária uma mudança fundamental no modo em que comunidades funcionam e como os indivíduos vivem. Esta mudança precisa envolver o sistema econômico, sistema de valor de indivíduos e de sociedade, convicções religiosas, direitos humanos e as rotinas diárias de indivíduos.

\subsection{Lei de SNUC para preservação ambiental}

A partir da década de 1970, instituições governamentais e sociedades civis interessadas elaboraram um plano traçando objetivos específicos necessários à conservação da natureza no Brasil. O plano trazia, ainda, a proposta de categorias de manejo dos recursos naturais, que não eram previstas na legislação vigente à época. Tal plano teve sua sanção governamental em 1982 e foi denominado Sistema Nacional de Unidades de Conservação da Natureza (SNUC).

Sem amparo legal, o Sistema não foi capaz de alcançar os objetivos que estabelecia. Apenas com a promulgação da Carta Magna, em 1988, foi dado o primeiro passo na normatização do tema, em obediência ao artigo 225 , inciso $1^{\circ}$, que determina a necessidade de:

"definir, em todas as unidades da Federação, espaços territoriais e seus componentes a serem especialmente protegidos, sendo a alteração e a supressão permitidas somente através de lei, vedada qualquer utilização que comprometa a integridade dos atributos que justifiquem sua proteção".

Ainda que a Constituição Federal preceitue a importância de um "meio ambiente ecologicamente equilibrado" e imponha ao poder público e à coletividade o dever de defendê-lo e preservá-lo para as presentes e futuras gerações, houve um lapso temporal de 12 anos para a resposta ao comando constitucional citado alhures, com a promulgação da Lei 9.985, de 18 de julho de 2000, responsável por instituir o Sistema Nacional de Unidades de Conservação.

A Lei de SNUC - como é conhecida - trata de um conjunto de diretrizes e procedimentos oficiais que possibilitam às esferas governamentais federal, estadual e municipal e à iniciativa privada a criação, implantação e gestão de unidades de conservação e, além disso, estabelece conceitos relevantes acerca de terminologias a elas relacionadas.

As unidades de conservação são na concepção de Milano (2001):

"espaços geográficos que, pelas características biofísicas singulares ou outras qualidades e potencialidades socioculturais, merecem receber do Estado proteção efetiva e permanente através de regimes especiais de administração que lhes garantam a integridade física sem perda de suas características e valores, mediante utilização de acordo com esses objetivos e adequado manejo".

No texto da Lei 9.985/00 são categorizadas 12 modalidades de unidades de conservação, subdivididas em dois grupos, considerando diferenças quanto à forma de proteção e usos permitidos.

As Unidades de Proteção Integral são aquelas 
áreas que precisam de maiores cuidados, pela sua fragilidade e particularidades, visando a "preservar a natureza, sendo admitido apenas o uso indireto dos seus recursos naturais". Já as Unidades de Uso Sustentável, buscam "compatibilizar a conservação da natureza com o uso sustentável de parcela dos seus recursos naturais.".

Para Barros (2000), os diferentes tipos de Unidades de Conservação decorreram de vários fatores, entre eles a sintonia de cientistas e administradores com as mudanças no panorama mundial da conservação ambiental, a ampliação do interesse social na questão, pressões internacionais e a concorrência entre organismos gestores e as suas diferentes políticas.

O grande objetivo da Lei de SNUC é fomentar a criação de Unidades de Conservação, que devem ser planejadas e administradas de forma integrada, assegurando que amostras significativas e ecologicamente viáveis das diferentes populações, habitats e ecossistemas estejam adequadamente representadas em todo o território nacional e das águas jurisdicionais, salvaguardando o patrimônio biológico existente (Brasil, 2000).

A criação de unidades de conservação pelos municípios representam uma importante ação para a efetivação da Lei de SNUC, uma vez que é capaz de proporcionar inúmeros benefícios, tais como a implementação do desenvolvimento sustentável; a preservação e a restauração da diversidade de ecossistemas naturais; a promoção de atividades científicas, de educação ambiental, ecoturismo e atividades recreativas; a garantia e a manutenção da qualidade, da produção e da quantidade das águas doces para o abastecimento humano; a promoção e geração de renda e estimulo ao progresso local e regional; proteção dos recursos naturais necessários à subsistência de populações tradicionais, respeitando e valorizando seu conhecimento e sua cultura e promovendo-as socioeconomicamente (Brasil, 2019).

Para que seja dada existência à unidade de conservação devem ser realizados estudos técnicos na área proposta, os quais trarão os elementos necessários para subsidiar a definição da sua categoria. No ato de criação de uma unidade de conservação devem ser indicadas ainda a denominação, a categoria de manejo, os objetivos, os limites, a área da unidade e o órgão responsável por sua administração, bem como a população tradicional beneficiária, no caso das Reservas Extrativistas e das Reservas de Desenvolvimento Sustentável, a população tradicional residente, quando couber, no caso das Florestas Nacionais, Florestas Estaduais ou Florestas Municipais, e as atividades econômicas, de segurança e de defesa nacional envolvidas.

Válido ressaltar que a escolha da categoria dentre as trazidas pela Lei de SNUC configura um importante passo no processo de criação da unidade, pois sua através dela pode-se oferecer oportunidades de promoção ao desenvolvimento social e econômico das comunidades localizadas no seu interior ou ao redor dela.

Depois de publicado o Ato de Criação da unidade de conservação, a prefeitura municipal deve incluí-la no Cadastro Nacional de Unidades de Conservação (CNUC), que é um banco de dados ligado ao Ministério do Meio Ambiente e responsável por organizar e manter informações padronizadas das unidades de conservação geridas pelos três níveis e por particulares.

Quanto à Mata do Louzeiro, pode-se observar que ainda que haja legislação municipal acerca do tema, não existiu preocupação por parte das autoridades municipais com a criação da unidade de conservação e sua inclusão no CNUC, claramente configurando a omissão do Poder Público diante do dever constitucional de preservação do Meio Ambiente.

Ressalta-se ainda que uma dura realidade enfrentada no procedimento de efetivação da Lei de SNUC é a dificuldade política capaz de proporcionar a criação de parques e também geri-los da forma que a lei prevê. Na prática, o processo é moroso em suas esferas política, financeira e legal e muitas vezes sem avanços significativos, ideias que não saem do plano teórico, os chamados parques de papel, não tendo eficácia no plano da realidade, social e jurídico, apenas parques virtuais, limitados às linhas em mapas oficiais, como bem estabelecem Terborgh e Van Schaik. (Pimentel, 2008).

Diante da importância da concentração de esforços para a defesa de um meio ambiente ecologicamente equilibrado, é perfeitamente cabível diante da omissão governamental, a propositura de Ação Popular. Esse instrumento constitucional 
permite que o cidadão, de forma direta, exerça a função fiscalizatória do Poder Público. Nos termos do Art. $5^{\circ}$, LXXIII da Constituição Federal:

“LXXIII - qualquer cidadão é parte legítima para propor ação popular que vise a anular ato lesivo ao patrimônio público ou de entidade de que o Estado participe, à moralidade administrativa, ao meio ambiente e ao patrimônio histórico e cultural, ficando o autor, salvo comprovada má-fé, isento de custas judiciais e do ônus da sucumbência”.

Cabível ainda a propositura de Ação Civil Pública, regida pela Lei n ${ }^{\circ}$ 7.347/85, que pode ser titularizada pelo Ministério Público, Defensoria Pública, União, pelos estados, municípios, autarquias, empresas públicas, fundações, sociedades de economia mista e associações interessadas, desde que constituídas há pelo menos um ano. Tal instrumento também tem o escopo de salvaguardar os interesses coletivos, entretanto, diferencia-se da Ação Popular quanto aos legitimados passivos, pois nela podem figurar como réus não apenas a Administração Pública, mas qualquer pessoa física ou jurídica que cause danos ao meio ambiente, aos consumidores em geral, a bens e direitos de valor artístico, estético, histórico, turístico e paisagístico.

Tais instrumentos são perfeitamente aplicáveis diante do propósito de romper a inércia do Poder Público no cumprimento do dever de implementação de unidades de conservação. A tutela jurisdicional pode ser pleiteada para diversos fins relacionados às unidades de conservação: para adoção de medidas de planejamento (elaboração de plano de manejo, definição de zona de amortecimento), para regularização fundiária (cadastro fundiário, avaliação de imóveis, desapropriação etc.) ou ações de efetiva estruturação e gestão (disponibilização de mão de obra, disponibilização de veículos e equipamentos para vigilância, combate a incêndio etc), ou ainda para buscar ressarcir prejuízos resultantes da responsabilidade pela reparação de eventuais danos materiais e morais coletivos ocasionados em decorrência da ausência da implantação das medidas em tempo hábil.

A Mata do Louzeiro já foi objeto de uma Ação Civil Pública em 2009 - no Processo no 0025285.56-2009.815.0011 movida pelo Ministério Público da Paraíba. A partir daí, a Prefeitura iniciou o processo de desapropriação da região da Mata, descrita como área de preservação permanente na legislação municipal. Passadas décadas de descaso, a área seria transformada no primeiro Jardim Botânico da cidade.

Acerca do tema, foi instaurado o Inquérito Civil $\mathrm{n}^{\circ}$ 16/2015 com a finalidade de investigar supostos atos de improbidade administrativa cometidos durante processo de desapropriação da área rural denominada "Sítio Louzeiro". O Ministério Público Estadual, entretanto, decidiu pelo arquivamento do mesmo, considerando não ter havido nenhuma irregularidade no procedimento em questão. Já o Ministério Público Federal optou por dar seguimento ao feito, denunciando os representantes legais do município junto ao Tribunal Regional Federal da $5^{\text {a }}$ Região.

O caso, entretanto, ainda não foi decidido nas vias judiciais e desapropriação resta revogada pela administração municipal. Em meio a esse cenário, a Mata do Louzeiro permanece sem receber a devida atenção por parte do Poder Público e sofre com a degradação ambiental desmedida diante da falta de fiscalização e efetiva regulamentação.

\section{Considerações Finais}

No nordeste brasileiro, a forma de ocupação dos espaços geográficos imprimiu alterações nas práticas produtivas e na relação sociedade e natureza. As diversas formas de utilização dos recursos ambientais, na maioria dos casos, causam a sua degradação. Contudo, algumas áreas ainda são portadoras de representações dos ecossistemas antes predominantes e, na tentativa de evitar seu completo desaparecimento, o processo de criação de áreas protegidas, através de UC, passa a ser uma resposta alternativa. 
A Mata do Louzeiro, inserida neste contexto, é um recorte geográfico e socioambiental que, apesar de ter sido palco de todos os momentos citados anteriormente, apresenta, além de significativa parcela da biodiversidade, em fauna e flora, uma beleza cênica bastante atrativa, fato que estimulou o poder público municipal a criar uma APP visando preservar o ambiente.

Entender a Mata do Louzeiro como uma Unidade de Conservação é compreender sua classificação como bem público, ou seja, que se presta a beneficiar sociedade, devendo ser amparada pela população envolvida e, indubitavelmente, pelo Poder Público. Um processo onde todos os atores envolvidos compreendam sua importância e participem da sua conservação, pautados no bem-estar humano, na educação ambiental, na gestão participativa e no desenvolvimento sustentável.

Existe um longo caminho para que o distanciamento dos entornos da Mata se aproximem dos tomadores de decisão acerca da região, para que as necessidades ambientais e sociais estejam acima de qualquer conflito, respeitando os recursos naturais que são patrimônio ambiental de Campina Grande, assim como compreendendo os anseios locais.

Nesta configuração, um dos mecanismos para minimizar conflitos é buscar a integração entre os atores envolvidos, não somente como facilitadores da gestão, mas, principalmente, como meio de democratizar as ações e alcançar formas socialmente justas de aproveitar os benefícios, sem fugir do objetivo maior que é a conservação dos recursos disponíveis.

A preocupação com as Unidades de Conservação se justifica uma vez que estas constituem uma forma efetiva de preservação da biodiversidade e dos recursos naturais. Mediante o desenvolvimento de ações que visem proteger a diversidade biológica, pode-se garantir a manutenção da capacidade de produção de riquezas para a atual e futuras gerações.

A criação de uma unidade de conservação que contemple a área ocupada pela Mata do Louzeiro tem o escopo de preservação de uma grande área com disponibilidade de recursos naturais - incluindo fontes de água doce -, bem como outros benefícios sociais e ecológicos usufruídos não só pela proteção da população adjacente, mas por toda a coletividade.

\section{Referências}

Barros, Lídia Almeida (2000). Vocabulário das unidades de conservação do Brasil. São Paulo: Arte \& Ciência; Marília: Unimar.

Brasil (1965). Código Florestal Brasileiro (Revogado): Lei no 4.771, de 15 de setembro de 1965. Brasília, DF.

Brasil (1988). Constituição da República Federativa do Brasil, de 05 de outubro de 1988. Brasília, DF.

Brasil (2000). Lei $n^{\circ}$ 9.985, de 18 de julho de 2000. Regulamenta o art. 225, $\S 1^{\text {o }}$, incisos I, II, III e VII da Constituição Federal, institui o Sistema Nacional de Unidades de Conservação da Natureza e dá outras providências. MMA/ SBF. Brasília, DF.

Brasil (2019). Ministério do Meio Ambiente. Roteiro para criação de unidades de conservação municipais [recurso eletrônico] / Ministério do Meio Ambiente, Secretaria de Biodiversidade, Departamento de Áreas protegidas - Brasília, DF.

Campina Grande (1990). Lei no 4.249, de 15 de março de 2005. Autoriza o Poder Municipal a criar o Jardim Botânico de Campina Grande e dá outras providências.

Campina Grande (1990). Lei Orgânica do município de Campina Grande, de 05 de abril de 1990.

Campina Grande (2006). Lei complementar $n^{\circ}$ 003, de 09 de outubro de 2006. Promove a revisão do Plano Diretor do Município de Campina Grande.

Campina Grande (2009). Lei complementar nº 042, de 24 de setembro de 2009. Institui o Código de Defesa do Meio Ambiente do Município de Campina Grande e dá outras providências.

Campina Grande (2019). Lei n 6.250, de 17 de dezembro de 2015. Cria o jardim botânico de Campina Grande e dá outras providências. 
Guedes, V. S. (2002). Impactos antrópicos no Sítio Louzeiro. Campina Grande-PB. Monografia (Bacharelado em Ciências Biológicas). Universidade Estadual da Paraíba-PB.

Lima, R. A. (2014). Louzeiro: a invenção de uma mata. 1960-2013. Campina Grande: espaço, paisagem e território. Dissertação (Mestrado em História) Universidade Federal de Campina Grande.

Milano, M. S. (2001). Unidades de Conservação - Técnicas, Lei e Ética para a Conservação da Biodiversidade. In: BENJAMIN, A. H. (Coord.). Direito ambiental das áreas protegidas: o regime jurídico das unidades de conservação. Rio de Janeiro: Forense Universitária.

Pimentel, D. S. (2008). Os "parques de papel" e o papel social dos parques. Tese de Doutoramento. Universidade de São Paulo.

Silva, E. P. (1999). Unidades de Conservação do Semi-Árido Brasileiro - Bioma Caatinga. PNCD/REDESERT. 